\title{
USING AUSTRALIAN CRYPTOCOCCAL SURVEILLANCE DATA TO IMPROVE AIDS SURVEILLANCE IN NSW
}

Shanti Raman ${ }^{1.2}$, John Rooney ${ }^{2}$, Tania Sorrell ${ }^{3}$, Sharon Chen ${ }^{3}$ Elizabeth Griggs ${ }^{1}$, Christine Roberts ${ }^{2}$

1. AIDS/Infectious Diseases Branch, NSW Health Department 2. Master of Applied Epidemiology Program, National Centre of Epidemiology \& Population Health, Australian National University, $A C T$

3. Department of Clinical Microbiology, Westmead Hospital

This article describes the results of a study in which the Australasian Cryptococcal Surveillance Register (ACSR) was compared with the NSW AIDS Register (NSWAR) to determine whether linking these databases could improve AIDS surveillance.

Surveillance of AIDS in Australia relies primarily on the passive receipt of notifications from doctors in each State and Territory ${ }^{1}$, supplemented by active surveillance carried out on an annual basis. AIDS is notifiable by medical practitioners in NSW under the Public Health Act 1991, based on the revised US Centers for Disease Control and Prevention (CDC) case definition ${ }^{2}$, but excluding individuals with CD4 counts below 200/pl if they do not have an AIDSdefining illness.

Studies have shown improved case reporting when active case finding is used in addition to passive surveillance. More complete AIDS surveillance has also been achieved through laboratory-based reporting of conditions indicative of AIDS $^{3}$. In 1994 the NSW Health Department undertook active case finding for AIDS in several public hospitals and private general practices. This estimated that medical practitioners reported only 82 per cent of AIDS cases ${ }^{4}$.

Extrapulmonary cryptococcosis is an AIDS-defining illness (ADI) that occurs in 5-10 per cent of patients with AIDS, and is one of the most common opportunistic infections ${ }^{5}$. Since March 1994 the Centre for Infectious Diseases and Microbiology, Westmead Hospital, Sydney, has been collecting data for the ACSR which aims to provide descriptive epidemiological data on cryptococcal disease in Australia. Information collected by the ACSR includes demographic details, site(s) of infection, underlying condition (including HIV infection), laboratory tests and biotype. All major public (hospital-based) and private laboratories, as well as some hospital infectious diseases physicians, have agreed to participate in the ACSR.

Linking two independent surveillance systems allows the assessment of the completeness of each system ${ }^{5}$. The aim of this study was to evaluate under-reporting of AIDS cases in NSW by determining the number of people with HIV infection who had cryptococcosis and therefore fulfilled the case definition for AIDS, but were not included on the NSWAR.

\section{METHOD}

The following information was obtained on all NSW residents who had been reported to the ACSR between March 1, 1994 and August 31, 1995, and had HIV infection recorded as an underlying condition: a name code comprising the first letters of the surname and given name, date of birth, sex, name and address of doctor requesting detection of Cryptococcus, and the cryptococcal biotype.

Cases on the ACSR were matched with those in the NSWAR using the date of birth, name code and sex. To be

\begin{tabular}{|c|c|c|c|}
\hline \multicolumn{4}{|c|}{$\begin{array}{l}\text { PEOPLE WITH HIV AND CRYPTOCOCCOSIS: COMPARISON OF } \\
\text { SURVEILLANCE BY THE AUSTRALIAN CRYPTOCOCCAL SURVEILLANCE } \\
\text { REGISTER (ACSR) AND THE NSW AIDS REGISTER (NSWAR), MARCH 1, } \\
1994 \text { TO AUGUST 31, } 1995\end{array}$} \\
\hline \multirow[t]{2}{*}{ NSWAR } & \multicolumn{3}{|c|}{ ACSR } \\
\hline & Yes & No & Total \\
\hline $\begin{array}{l}\text { Yes } \\
\text { No } \\
\text { Total }\end{array}$ & $\begin{array}{l}38 \\
19 \\
57\end{array}$ & $\begin{array}{c}18 \\
9 * \\
27\end{array}$ & $\begin{array}{l}56 \\
28 \\
84\end{array}$ \\
\hline
\end{tabular}

* Estimated using Chandra Sekar-Deming method

a match, cases had to fulfil all three identifiers, including some part of the name code (the NSWAR records the first two letters of the surname and given name). Cases not reported to the NSWAR were investigated by local Public Health Units (PHUs). Referring doctors were urged to complete AIDS notification forms if they had not done so already.

We used the Chandra Sekar-Deming (CSD) method to compare the completeness of reporting of the ACSR and the NSWAR for cryptococcosis as an $\mathrm{ADI}^{6}$.

\section{RESULTS}

During the 18-month study period 57 NSW residents who had Cryptococcus and HIV infections were reported to the ACSR. As of October 31, 1995, 38 (67 per cent) of these had been reported to the NSWAR and 19 (33 per cent) had not. Follow-up of the 19 unreported cases led to 13 cases being reported to the NSWAR with AIDS. Of the six remaining unreported cases, two resided outside NSW, two could not be traced and two are yet to be reported.

During the same period, 56 NSW residents were reported to NSWAR with Cryptococcus infection as an ADI at the time of initial AIDS diagnosis. Of these 56, 38 (68 per cent) were on the ACSR. Of these 38,21 had cryptococcosis recorded as an $\mathrm{ADI}$ and 17 had another ADI. The remaining 18 (32 per cent) were not reported to the ACSR.

Table 2 compares the completeness of reporting of the ACSR and the NSWAR. Based on the CSD method, the completeness of reporting of the ACSR was 68 per cent (57/84), and that of the NSWAR was 66 per cent (56/84). The number of potential AIDS cases with cryptococcosis infection that was missed by both systems was estimated to be nine cases, and the combined completeness of the two systems was 89 per cent.

\section{DISCUSSION}

Cryptococcosis is the most common life-threatening fungal infection in people with AIDS. Of those who develop cryptococcosis, it is the initial ADI in 40-45 per cent $t^{6}$. The epidemiology of cryptococcosis is changing globally, with a documented increase in incidence in western countries? Since the only way to diagnose cryptococcal disease is through definitive laboratory identification, it lends itself well to a laboratory-based surveillance system. Our study found that linking the ACSR and the NSWAR improved 
AIDS surveillance - one-third of the cases with HIV in the cryptococcal database had not been notified as AIDS cases.

In the past, the main reasons given by doctors for not reporting people with AIDS were difficulties with reporting procedures and the complicated AIDS case definition, concerns about maintaining patient confidentiality and inadequate Health Department feedback on AIDS surveillance data ${ }^{8}$. However, in this study, the follow-up of non-reported cases was carried out by PHUs and we were unable to determine the factors that led to non-reporting or delayed reporting.

The CSD method assumes that the two systems compared are independent, that all events (diagnoses) identified are true events, and that all true matches are identified ${ }^{6}$. The ACSR relies on the voluntary reporting of cryptococcal cases by busy physicians and laboratory personnel. Poor reporting practices of infectious diseases by medical practitioners have been well documented ${ }^{9}$. However, since the end of this study, anecdotal reports suggest that reporting to ACSR by medical practitioners and laboratories has improved, with compliance now approaching 95 per cent. Collation of data for the first 12 months of the ACSR has identified 75 NSW residents with both Cryptococcus and HIV infections.

People with AIDS and cryptococcosis may not be identified to have cryptococcosis on the NSWAR unless it was the ADI. Cryptococcosis in HIV-positive patients is said to occur when the CD4 lymphocyte count is in the range 75-125/pl, a level lower than that at which other ADIs such as tuberculosis, Kaposi's sarcoma and lymphoma occur ${ }^{10}$.

In our study only two cases could not be identified or matched. This could have been for any number of reasons such as laboratory or clerical error, fictitious reports (if the patient decides to use a pseudonym), or inaccurate data transfer. Some of the non-reported cases may have been reported after October 1995, either with cryptococcosis or some other $\mathrm{ADI}$.

Improving prophylaxis of opportunistic infections in people with advanced HIV disease will lead to shifts in the timing and severity of the occurrence of $\mathrm{ADI}^{11}$. Cryptococcosis may take on more prominence as an ADI when prophylaxis for Pneumocystis carinii pneumonia (PCP) is used ${ }^{12}$. On the other hand, the occurrence of cryptococcosis may be delayed or prevented by the use of prophylaxis for candidiasis ${ }^{12}$. We believe the ACSR will play a valuable role in monitoring and documenting the changing epidemiology of not only cryptococcal disease in Australia, but in the manifestations of AIDS as well.

Given the high social and economic costs of AIDS, it is important both for epidemiologic studies and resource planning to have as complete and timely surveillance data as possible. Annual linkage of ACSR and the NSWAR can be done quickly and with relative ease, and would be a valuable contribution to AIDS surveillance.

\section{ACKNOWLEDGMENTS}

The Master of Applied Epidemiology Program is funded by the Commonwealth Department of Health and Family Services. The authors are grateful to Simon Herbert, who developed the ACSR.

1. Kaldor $J$ et al. The acquired immunodeficiency syndrome in Australia: incidence 1982-1991. Med J Aust 1993;158:10-17.

2. Centers for Disease Control and Prevention. 1993 revised classification system for HIV infection and expanded surveillance case definition for AIDS among adolescents and adults. MMWR 1992; 41(No RR-17):1-19. 3. Trino R, McAnaney J, Fife D. Laboratory-based reporting of AIDS. $J$ Acquir Immun Defic Syndr 1993; 6:1057-1061.

4. Menzies R, Griggs E. Report: Improvement of AIDS surveillance in NSW. February 1995. Public Health Division, AIDS/Infectious Diseases Branch, New South Wales Health Department.

5. Chandra Sekar C, Deming WE. On a method of estimating birth and death rates and the extent of registration. J Am Stat Assoc 1949; 44:101-115.

6. Treatment for HIV-related fungal infections. HIV: An Electronic Media Information Review. 2:14:1-7.

7. Knight FR, Mackenzie DW, Evans BG, Porter K, Barrett NJ, White GC. Increasing incidence of cryptococcosis in the United Kingdom. I Infect 1993; 27:185-191.

8. McAnulty JM, Rubin GL, Rushworth RL, Kaldor J. Underreporting of AIDS, New South Wales, 1988-1989. Med J Aust 1992; 156:452-455.

9. Rushworth RL, Bell SM, Rubin G, Hunter RM, Ferson MJ. Improving surveillance of infectious diseases in New South Wales. Med J Aust 1991; 154:828-831.

10. Crowe SM, Carlin JB, Stewart KI, Lucas CR, Hoy JF. Predictive value of CD4 lymphocyte numbers for the development of opportunistic infections and malignancies in HIV-infected persons. J Acquir Immun Defic Syndr 1991; 4:770-776.

11. Stoeckle M, Douglas RG. Infectious Diseases (Contempo 1995). JAMA 1995; 273:1686-1688.

12. Hoover DR, Saah AJ, Bacellar H, Phair J et al. Clinical manifestations of AIDS in the era of pneumocystis prophylaxis. $N$ Engl J Med 1993; 329:1992-1996.

\section{PUBLIC HEALTH EDITORIAL STAFF}

The editor of the NSW Public Health Bulletin is Dr Michael Frommer, Director, Research and Development, NSW Health Department. Dr Lynne Madden is production manager.

The Bulletin aims to provide its readers with population health data and information to motivate effective public health action. Articles, news and comments should be 1,000 words or less in length and include a summary of the key points to be made in the first paragraph. References should be set out using the Vancouver style, the full text of which can be found in British Medical Journal 1988; 296:401-5.

Please submit items in hard copy and on diskette, preferably using WordPerfect, to the editor, NSW Public Health Bulletin, Locked Mail Bag 961, North Sydney 2059. Facsimile (02) 3919029.

Please contact your local Public Health Unit to obtain copies of the NSW Public Health Bulletin. 